\title{
Sliding Mode Control Approach for Maximum Power Tracking in Single-Phase Grid-Connected Photovoltaic Systems
}

\author{
Ouadia El Maguiri ${ }^{1}$, Abdelmajid Farchi ${ }^{2}$, El Mustapha Louragli ${ }^{2}$ \\ ${ }^{1}$ (Department of Electrical Engineering, CRMEF, Settat, Morocco \\ ${ }^{2}$ (Laboratory of Mechanical Engineering, Industrial Management \&Innovation \\ FST, University Hassan First,Settat, Morocco )
}

\begin{abstract}
This work presents a new control method to track the maximum power point of a single-phase gridconnected photovoltaic (PV) system. This converter is built on two stages: a DC/ DC stage and a DC/ AC stage. The two blocks are bound by a DC voltage intermediate bus. We seek the achievement of three control objectives: (i) maximum power point tracking (MPPT) of (PV) module. (ii) tight regulation of the DC bus voltage and (iii) unity power factor (PF) in the grid. To meet these objectives, a multi-loop controller is designed using the sliding mode technique based on an averaged nonlinear model of the whole controlled system. It is formally shown, through analysis and simulation results that the developed strategy control actually meets its objectives.
\end{abstract}

Keywords: photovoltaic system, maximum power point (MPP), boost converter, sliding mode, unity power factor, lyapunov.

\section{INTRODUCTION}

Due to the requirement for environmental preservation and dramatic increase in energy consumption over the last decades, most countries have decided to strongly promote and develop clean and sustainable power generation sources. Also, governments encourage resorting to such energy solutions through significant tax credits.

Nowadays, renewable energy sources are widely used and particularly (PV) energy systems have become widespread everywhere. Indeed, PV systems present several features e.g high dependability, simplicity of allocation, absence of fuel cost, low maintenance and lack of noise due to the absence of moving parts. All these considerations assure a promising role for PV generation systems in the near future.

The grid-connected PV systems consist of an array of solar module, a DC-DC power converter, a DC$\mathrm{AC}$ converter and a control system, the complete scheme is presented in fig 1

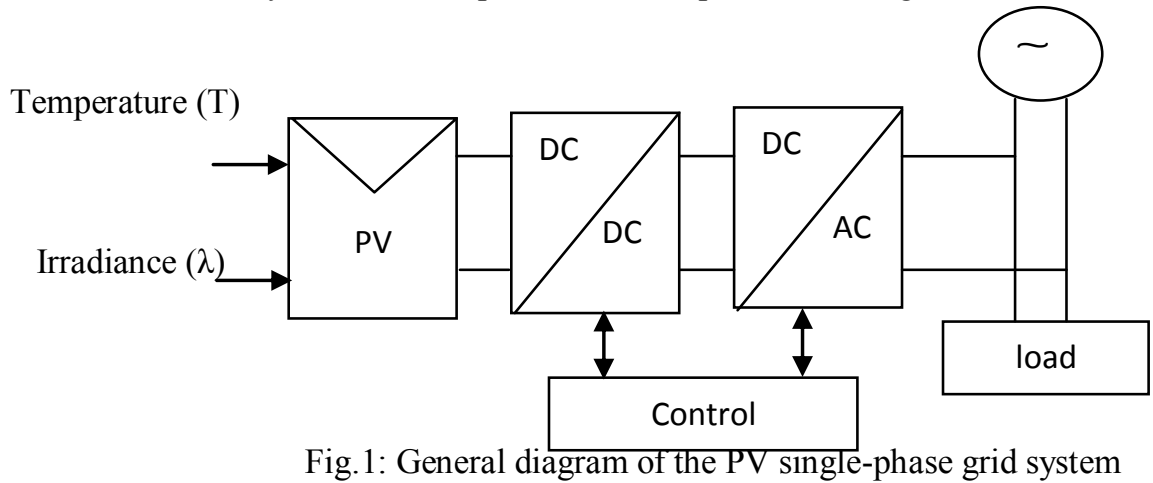

Due to the switching functions of the converters and inverters, grid-connected PV systems are highly nonlinear systems, advanced and efficient control schemes are essential to ensure the operation over a wide range of operating points. Moreover, dependence of the power generated by a PV array and its MPP (maximum power point) on atmospheric conditions (temperature and irradiance) necessitating continuous tuning array terminal voltage if maximum power is to be transferred. This result is readily be seen in the power-voltage $(\mathrm{P}-\mathrm{V})$ characteristics of PV arrays as shown in Fig. 4 and Fig. 5.

In the literature, different techniques to maximize (PV) power transfer to various loads have been reported, including: perturb and observe $(\mathrm{P} \& \mathrm{O})$ method ([1], [2]), the incremental conductance method (IncCond) ([3],[4], [5]), the open circuit voltage method, the short circuit method, the Ripple Correlation Control (RCC) method [6] and artificial neuronal networks based algorithms([7]-[8]), amongst others.

In the first method mentioned above, $(\mathrm{P} \& \mathrm{O})$, the output power has an oscillatory behavior about the maximum power point (MPP) which can be minimized by reducing the perturbation step size. However, a small 
perturbation size slows down the MPPT. Also, the equilibrium point is not always achieved, obtaining a local maximum instead of a global maximum. The artificial neuronal network has an involved structure and a singularity problem in (RCC) and (IncCond) methods

In this paper, a new control method for MPPT is proposed. A nonlinear sliding mode controller ([9][10]) has been designed to track the maximum power point in the sense to extract the maximum power from photovoltaic generator regardless of temperature and solar radiation. In addition, the control of the DC-AC power inverter of the PV system has been designed to inject electrical power to the electrical network by means of a PI control. So, the global control makes possible extract the maximum power of the PV system, inject active power and regulate the input voltage of the DC-AC power inverter.

The rest of the paper is organized as follows: in Section II, the system modeling is presented; Section III is devoted to the controller design; the controller tracking performances are illustrated through numerical simulations in Section IV; a conclusion and a reference list end the paper.

\section{PResentation ANd Modeling OF GRID CONNECTEd PV SYSTEM}

The configuration of a single-phase grid connected photovoltaic system is shown in Fig 2, it consists of a solar array, an input capacitor $C_{i}$, a boost DC-DC converter which is used for boosting the array voltage and achieving MPPT for PV array, a DC link capacitor $C_{d c}$, a single phase full-bridge inverter (including fours power semiconductors) with filter inductor $L_{g}$ which converters a DC input voltage into an AC sinusoidal voltage, and finally an isolation transformer. By means of appropriate switch signals $u_{1}$ and $u_{2}$, the converter is controlled to make the output current in phase with the utility voltage $e_{g}$ and so obtain a power factor (PF) of unity.

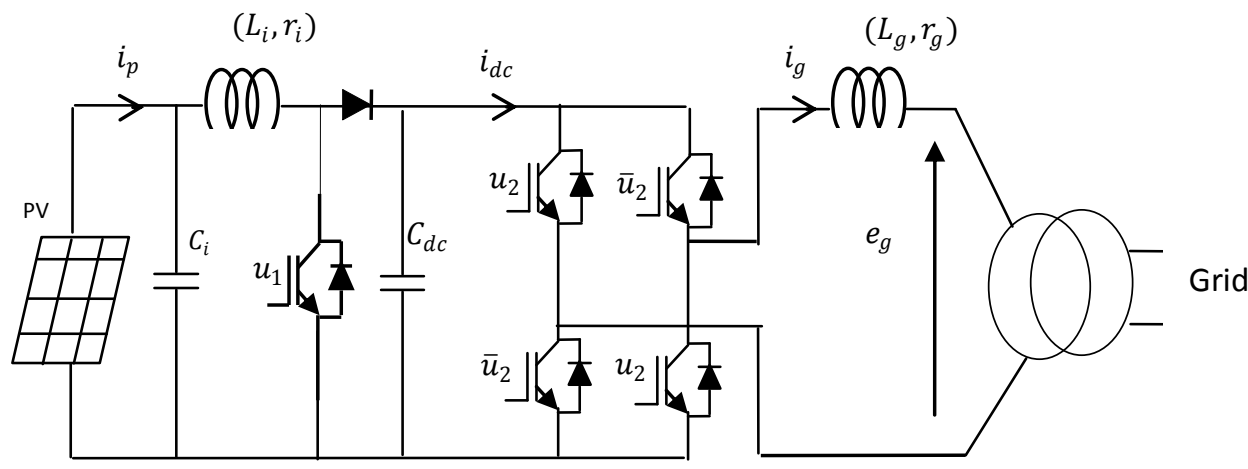

Fig.2: typical configuration of single stage grid connected pv system

\subsection{Photovoltaic generator model}

The direct conversion of the solar energy into electrical power is obtained by solar cells. The equivalent circuit of PV module is shown in fig 3. (see e.g. [11], [12], [13]).

The traditional $\left(I_{p}-V_{p}\right)$ ideal characteristics (i.e $R_{s}=0, R_{s h}=\infty$ ) of a solar array are given by the following equation:

Where

$$
I_{p}=I_{p h}-I_{o}\left\{\exp \left(A V_{p}\right)-1\right\}
$$

$$
\begin{gathered}
A=\frac{q}{\gamma K T} \\
I_{p h}=\left[I_{S O R}+K_{1}\left(T-T_{r}\right)\right] \frac{\lambda}{1000} \\
I_{O}=I_{o r}\left[\frac{T}{T r}\right]^{3} \exp \left[\frac{q E_{G O}}{\gamma K}\left(\frac{1}{T r}-\frac{1}{T}\right)\right]
\end{gathered}
$$

Where $I_{p h}$ is the photocurrent (generated current under a given radiation), $I_{O}$ is the cell reverse saturation current, $I_{S O R}$ is the cell saturation current at $T_{r}, I_{S O R}$ is the short circuit current at $298.15 \mathrm{k}$ and $1 \mathrm{KW} / \mathrm{m}^{2}, K$ is the short circuit current temperature coefficient at $I_{S O R} . \lambda$ is the solar radiation, $E_{G O}$ is the band gap for silicon, $\gamma$ is 
the ideality factor,$T_{r}$ is the reference temperature, $T$ is the cell temperature, $K$ is the Boltzmans constant and $q$ is the electron charge, the analytical expressions of $I_{p h}$ and $I_{o r}$ can be found in many places, see [9]. Here let us just note that these only depend on the temperature $T$ and radiation $\lambda$. The pv array module considered in this paper is the SM55 type involving 36 series connected mono-crystalline cells and the array's electrical characteristics are described in table1.

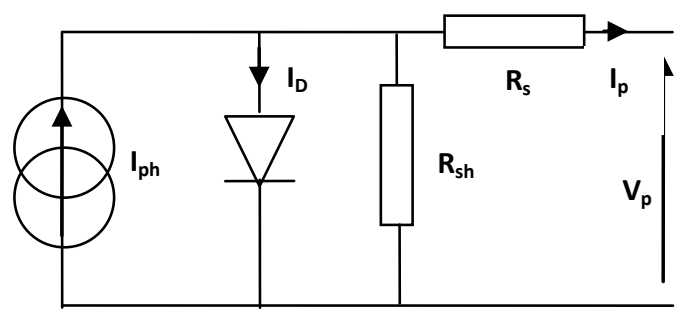

Fig.3: PV module circuit

Table1. Electrical specifications for the solar module SM55

\begin{tabular}{l|l|l}
\hline \hline Parameter & Symbol & Value \\
\hline Maximum power & Pm & $55(\mathrm{~W})$ \\
Short circuit current & Iscr & $3,45(\mathrm{~A})$ \\
Open circuit voltage & Voc & $21,7(\mathrm{~V})$ \\
Maximum power voltage & $\mathrm{Vm}$ & $17,4(\mathrm{~V})$ \\
Maximum power current & $\mathrm{Im}$ & $3,15(\mathrm{~A})$ \\
Number of parallel modules & $\mathrm{Np}$ & 1 \\
Number of series modules & $\mathrm{Ns}$ & 36 \\
\hline \hline
\end{tabular}

The associated power-voltage $(\mathrm{P}-\mathrm{V})$ characteristics under changing climatic conditions (temperature and radiation) are shown in fig 4 and 5 .

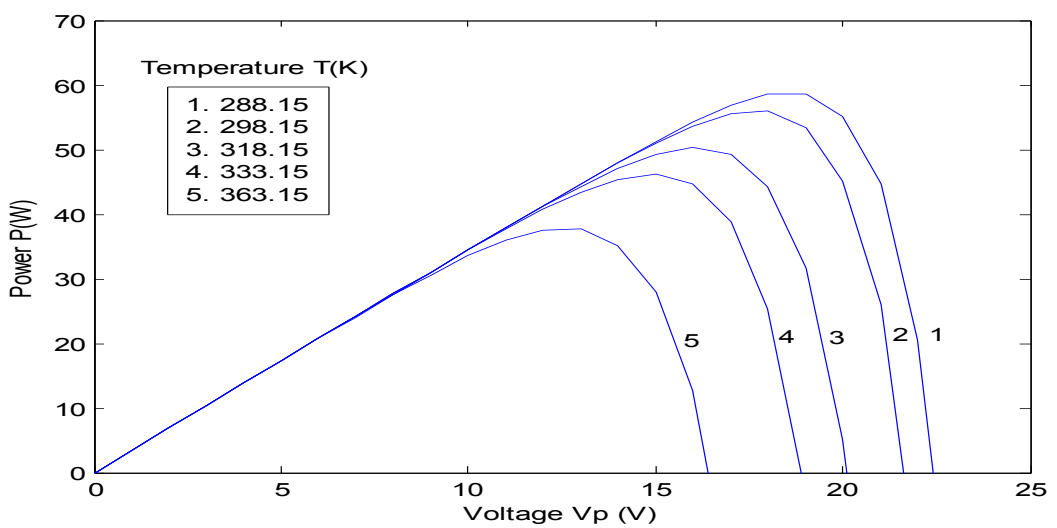

Fig.4: $(P-V)$ characteristics of The PV module SM55 with constant radiation and varying temperature

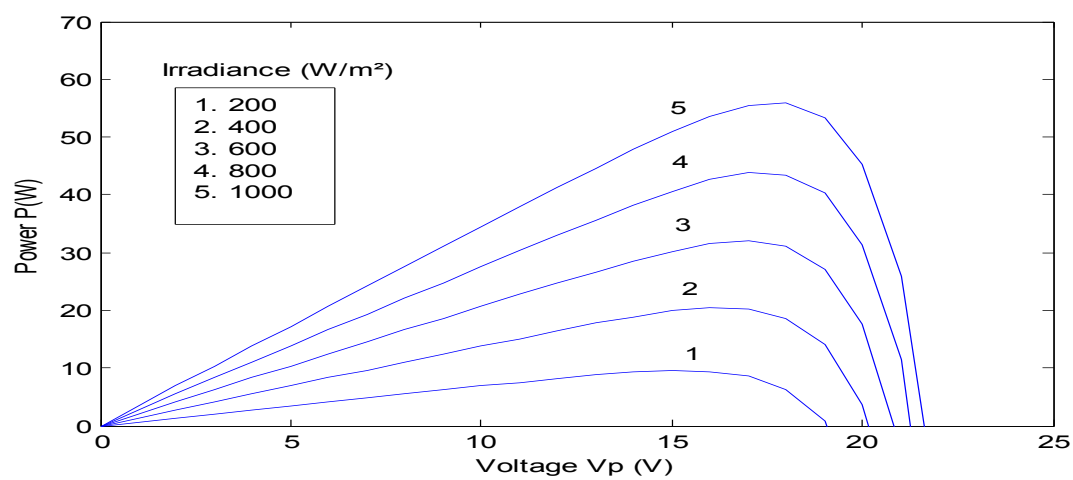

Fig.5: (P-V) characteristics of The PV module SM55 with constant temperature and varying radiation 


\subsection{Overall system model}

The control input $u_{1}$ and $u_{2}$ of the boost converter and for the inverter respectively are a PWM signals (pulse width modulation) taking values in the set $\{0,1\}$, they vary from one period to another and their variations can determine the trajectories of the state variables of the converter.

Applying the kirchoff's laws, one obtains the following averaged model [14].

$$
\begin{aligned}
& C_{i} \dot{x}_{1}=-x_{2}+\vec{\imath}_{p} \\
& L_{i} \dot{x}_{2}=-\left(1-\mu_{1}\right) x_{3}-r_{i} x_{2}+x_{1} \\
& C_{d c} \dot{x}_{3}=\left(1-\mu_{1}\right) x_{2}+\left(1-2 u_{2}\right) x_{4} \\
& L_{g} \dot{x}_{4}=-\left(1-2 \mu_{2}\right) x_{3}-r_{g} x_{4}-\bar{e}_{g}
\end{aligned}
$$

Where $x_{1}, x_{2}, x_{3}, x_{4}, u_{1}, u_{2}$ and $\vec{l}_{p}$ denote respectively the means values, over a period of cutting of variables $v_{p}, i_{c i}, V_{d c}, i_{g}, \mu_{1}, \mu_{2}$ and $i_{p}$. And where $r_{i}$ and $r_{g}$ are respectively the equivalent series resistances (ESR) of input inductance $L_{i}$ and output filter $L_{g}$. The quantities $\mu_{1}, \mu_{2}$, commonly called duty ratios, vary continuously in the interval $[0,1]$.

Note that the mathematical model $(2 \mathrm{a}-\mathrm{d})$ is non linear because of the products involving the state variables and input signals. Taking into account these nonlinearities, a nonlinear controller using the sliding mode technique ([9], [10]) will be done in the next paragraph.

\section{CONTROLLER DESIGN}

The converter control strategy must be developed to:

i) Ensure a global stability of closed loop system

ii) Achieve the MPPT (maximum power tracking) side of the PV cell by setting the operating point power/voltage

iii) Ensure the setting of the DC bus voltage

iv) Obtain unity power factor and low harmonic distortion at the output

\subsection{Controlling the boost converter to meet MPPT}

Recall that the control objective is to enforce the output power $p(w)=v_{p} i_{p}$ to track as accurately as possible its optimal point $\left(p_{\text {opt }}, v_{\text {popt }}\right)$ whatever the radiation $(\lambda)$ and the temperature $(T)$. Specifically, if the derivative $y=\frac{d p}{d v_{p}}$ is made equal to $y_{r e f}=0$, then maximal power $P_{o p t}$ is captured. The control circuit must steer the derivative $y$ to zero, by acting on the duty cycle $\mu_{1}$. At the optimal point, one has

$$
\frac{d p}{d v_{p}}=\tau_{p}+v_{p} \frac{d \tau_{p}}{d v_{p}}=0
$$

In this section, the purpose is to design a sliding mode controller (SMC). The basic (SMC) design procedure in our case is performed in two steps. Firstly, the choice of sliding surface $\sigma$ according to the tracking error, while the second step is the design of a Lyapunov function that can satisfy the necessary sliding condition $\sigma \dot{\sigma}<0$. During this sliding regime, the closed loop control system becomes insensitive to external perturbation signals, modeling errors and parameter variations. Let us introduce the tracking error $\varepsilon_{1}$ defined by

$$
\varepsilon_{1}=y-y_{\text {ref }}
$$

In view of (1), its dynamics is given by

$$
\dot{\varepsilon}_{1}=-\frac{A I_{0}}{C_{i}} \exp \left(A x_{1}\right)\left(2+A x_{1}\right)\left(\bar{\imath}_{p}-x_{2}\right)
$$

The second derivative of $\varepsilon_{1}$ is given by

$$
\ddot{\varepsilon}_{1}=-\frac{A i_{0}}{C_{i}}\left[\frac{A}{C_{i}}\left(3+A x_{1}\right)\left(\bar{l}_{p}-x_{2}\right)^{2}+\left(2+A x_{1}\right)\left(\frac{\bar{d} i_{p}}{d t}-\dot{x}_{2}\right)\right](6)
$$

In view of (2b), $\ddot{\varepsilon}_{1}$ can be rewritten as follows

Where

$$
\ddot{\varepsilon}_{1}=\Delta_{0}+\Delta_{1} \mu_{1}
$$

$\Delta_{0}=-\frac{A I_{0}}{C_{i}} \exp \left(A x_{1}\right)\left[\frac{A}{C_{i}}\left(3+A x_{1}\right)\left(\vec{l}_{p}-x_{2}\right)^{2}+\left(2+A x_{1}\right)\left(\frac{d \bar{l}_{p}}{d t}-\frac{1}{L_{i}}\left(-r_{i} x_{2}+x_{1}-x_{3}\right)\right)\right]$

And

$$
\Delta_{1}=\frac{A I_{0}}{L_{i} C_{i}} \exp \left(A x_{1}\right)\left(2+A x_{1}\right) x_{3}
$$

Equation (7) shows that the output $\left(y=\frac{d p}{d v_{p}}\right)$ has the relative degree of 2 with respect to the control input $\mu_{1}$. 
The crux of (SMC) scheme is the definition of a sliding surface $\sigma$ along which the sliding motion is to take place, this sliding surface is defined by:

$$
\sigma=\dot{\varepsilon}_{1}+\lambda_{1} \varepsilon_{1}
$$

Where $\lambda_{1}$ is positive design parameter chosen such that the polynomial $p(s)=s+\lambda_{1} s$ is Hurwitz and where $s$ denotes the Laplace variable.

If a control law enforces the trajectory such that the sliding surface $\sigma=0$ holds true, then the tracking error converges asymptotically to origin as prescribed by:

$$
\dot{\varepsilon}_{1}+\lambda_{1} \varepsilon_{1}=0
$$

In order to demonstrate stability, we adopt the lyapunov candidate function given as:

$$
V_{1}=\frac{1}{2} \sigma^{2}
$$

The time derivative of the lyapunov function in (12) can be computed as follows

$$
\dot{V}_{1}=\sigma \dot{\sigma}
$$

This suggests choosing the control law $u_{1}$ so that:

$$
\dot{\sigma}=-k_{1} \operatorname{sign}(\sigma)
$$

Where $\operatorname{sign}(\sigma)$ denotes the sign function and $k_{1}$ being a design parameter. Indeed combinig (12) and (14) one gets that:

$$
\dot{V}_{1}=\sigma \dot{\sigma}=-k_{1} \sigma \operatorname{sign}(\sigma)
$$

Which is a negative-definite function of $\sigma$. Then the necessary sliding condition is verified and Lyapunov stability is guaranteed.

Equations(7), (10) and (14) can be solved in order to determine the control variable, we obtain the following controller

$$
u_{1}=\Delta_{1}^{-1}\left(-k_{1} \operatorname{sign}(\sigma)-\lambda_{1} \dot{\varepsilon}_{1}-\Delta_{0}\right)
$$

Indeed, with this choice, we have $\dot{V}_{1}=-k_{1}|\sigma|<0$, which imply that the equilibrium $\sigma=0$ is globally asymptotically stable.

The signum function design $\operatorname{sign}($.$) induces a chattering phenomenon that is by no means suitable in practical$ situations. The design function that is commonly used in the sliding mode practice include $\tanh \left(k_{0} \sigma\right)$ where tanh denotes the hyperbolic tangent function and $k_{0}$ is a high value. Particularly, recall that one has:

$$
\lim _{k_{0} \rightarrow \infty} \tanh \left(k_{0} \sigma\right)=\operatorname{sign}(\sigma)
$$

\subsection{Controlling the inverter to meet unity PF in the grid \\ 3.2.1Unity PF objective}

The unity PF objective means that the grid current $i_{g}$ should be sinusoidal and in phase with the (AC) grid supply voltage $\bar{e}_{g}$. It amounts to ensuring current harmonics rejection. We therefore seek a regulator that enforces the current $x_{4}$ to tack a reference signal $x_{4}^{*}$ of the form

$$
x_{4}^{*}=\beta \overline{e_{g}}
$$

When $\beta \in I R^{+}$

The regulator will now be designed using the sliding mode technique [10]

Consider the tracking error $\varepsilon_{2}$ defined by

And the function

$$
\varepsilon_{2}=x_{4}-x_{4}^{*}
$$

$$
\sigma_{2}=\varepsilon_{2}+\lambda_{2} \int \varepsilon_{2} d t
$$

Where $\lambda_{2}$ is a design parameter. The control objective is to enforce the system state to reach the sliding surface $\sigma_{2}$ and stay therein. Then the tracking error $\varepsilon_{2}$ undergoes the equation:

$$
\dot{\varepsilon}_{2}+\lambda_{2} \varepsilon_{2}=0
$$

The tracking objective thus reformulated suggests the following Lyapunov function

$$
V_{2}=\frac{1}{2} \sigma_{2}^{2}
$$

On other hand, one gets from (20), that

$$
\dot{\sigma}_{2}=\dot{\varepsilon}_{2+} \lambda_{2} \varepsilon_{2}
$$

This suggests choosing the control law $\mu_{2}$ so that:

$$
\mu_{2}=\frac{L_{g}}{x_{3}}\left[-k_{2} \operatorname{sign}\left(\sigma_{2}\right)-\lambda_{2} \varepsilon_{2}+\dot{x}_{4}^{*}+\frac{r_{g}}{L_{g}} x_{4}+\frac{\bar{e}_{g}}{L_{g}}\right]
$$

Where $k_{2}>0$ is a design parameter.

Indeed, combining (19) and (20) and (22), one gets:

$$
\dot{V}_{2}=\sigma_{2} \dot{\sigma}_{2}=-k_{1} \sigma_{2} \operatorname{sign}\left(\sigma_{2}\right)
$$

Which is a negative-definite function of $\sigma_{2}$, Therefore global asymptotic stability is achieved and $\varepsilon_{2}$ tends to zero, and the (PF) is asymptotically achieved. 


\subsubsection{DC bus voltage regulation}

The aim is now to design a tuning law for the ratio $\beta$ in (18) in such a way that the DC bus voltage $x_{2}$ be regulated to a given reference $x_{2}^{*}>0$, to this end, the following PI control law is used:

Where

$$
\beta=F(s) z
$$

$$
\begin{aligned}
& F(s)=k_{p}+k_{i} \frac{1}{s} \\
& z=x_{2}-x_{2}^{*}
\end{aligned}
$$

Where $s$ denotes the Laplace variable.

The bode diagram of figure 6 shows the frequency response of the transfer function $F(s)$.



Fig. 6 Bode diagram of $\mathrm{F}(\mathrm{s})$

The main results of the paper are now summarized in the following proposition.

Proposition 1. Consider the closed loop system consisting of the single phase grid-connected PV system, of fig. 1 represented by its averaged model (2a-d), and the controller composed of the control laws (16), (23) and (25). Then one has the following results:

i) The closed loop system is globally asymptotically stable

ii) The tracking error $\varepsilon_{1}$ vanishes exponentially, implying MPPT achievement.

iii) The error $x_{2}-x_{2}^{*}$ converge to zero guaranteeing a tight regulation of the DC bus voltage.

iv) The error $\varepsilon_{2}$ converge to zero ensuring a unity $\mathrm{PF}$

\section{Simulation RESULTS}

The performances, described by proposition 1 of the proposed nonlinear sliding mode controller are now illustrated by simulation. The experimental setup is described by Fig.7 and is simulated using the MATLAB software. The characteristics of the controlled system are listed in table II. The control design parameter which proved to be convenient are given values of table III. The resulting control performances are shown by Figs 8 to 11 . 


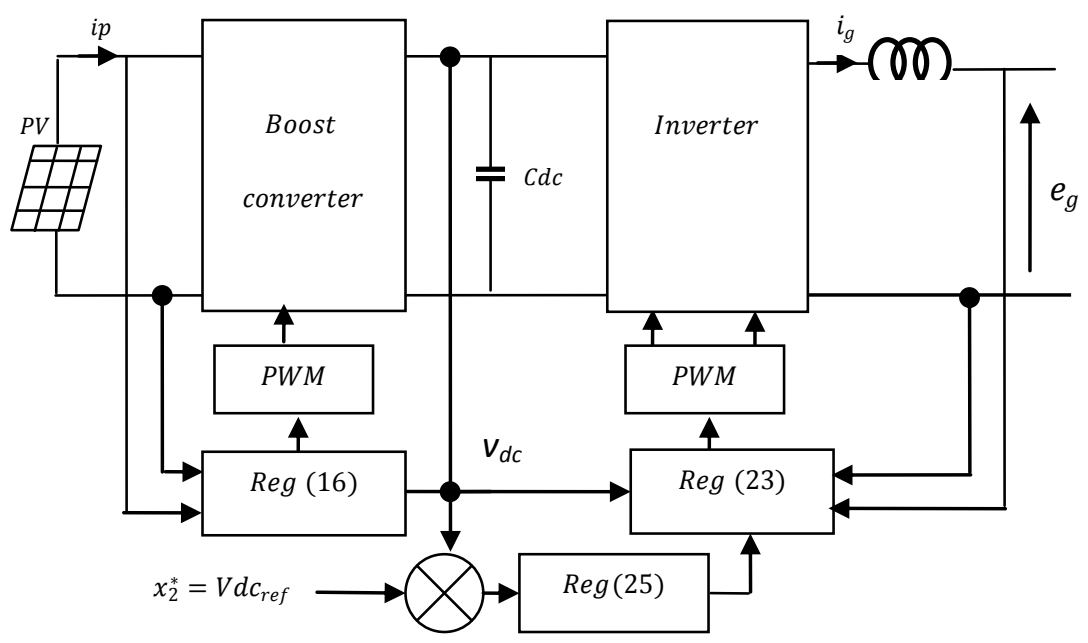

Fig.7 Experimental bench

TABLE II. Characteristics of controlled system

\begin{tabular}{l|l|l}
\hline \hline Parameter & Symbol & Value \\
\hline PV array & PV model & SM55 \\
Boost converter & $C_{i}$ & $47(\mathrm{mF})$ \\
& $L_{i}$ & $3.5(\mathrm{mH})$ \\
DC link capacitor & $r_{i}$ & $0.65(\Omega)$ \\
Grid filter inductor & $C_{d c}$ & $4.7(\mathrm{mF})$ \\
& $L_{g}$ & $2.2(\mathrm{mH})$ \\
Grid & $r_{g}$ & $0.47(\Omega)$ \\
& Transformer ratio & $22: 220$ \\
& AC source & $220(\mathrm{~V})$ \\
\hline \hline
\end{tabular}

TABLE III. Controller parameters

\begin{tabular}{l|c|l}
\hline Parameter & symbol & Value \\
\hline Design parameter & $\lambda_{1}$ & 15 \\
& $k_{1}$ & $10 \times 10^{2}$ \\
& $k_{2}$ & $3.5 \times 10^{2}$ \\
& $\lambda_{2}$ & 15 \\
PI-regulator & $k_{p}$ & $1 \times 10^{-2}$ \\
& $k_{i}$ & 1 \\
Desired DC bus voltage & $x_{2}^{*}$ & $30(\mathrm{~V})$ \\
\hline \hline
\end{tabular}

Fig 8 illustrates the tracking results of controlled system in presence of temperature change. The change are carried out between $288.15 \mathrm{~K}$ and $333.15 \mathrm{~K}\left(15^{\circ} \mathrm{C}\right.$ and $\left.60^{\circ} \mathrm{C}\right)$, meanwhile the radiation $\lambda$ is kept constant, equal to $1000 \mathrm{~W} / \mathrm{m}^{2}$. The figure shows that the captured PV power varies between $46.5 \mathrm{~W}$ and $54.1 \mathrm{~W}$. These values correspond (see fig. 4) to the maximum power point of the curves associated to the mentioned temperatures respectively. It is observed that the extracted current $\tau_{p}$ and $i_{c i}$ varies whenever the extracted power $\mathrm{P}(\mathrm{w})$ varies. Fig (8) illustrate also that the DC bus voltage $x_{3}$ is regulated to its desired value (30V). Fig (9) shows that the grid current $i_{g}$ remains most time in phase with the supply voltage $e_{g}$ complying with the PFC requirement. The current frequency is constant and equal to voltage $e_{g}$ frequency; its amplitude varies with the extracted power value.

In fig (10), sliding control MPPT is tested under sudden change of radiation from $400\left(\mathrm{~W} / \mathrm{m}^{2}\right)$ to 1000 $\left(\mathrm{W} / \mathrm{m}^{2}\right)$. While the temperature is constant equal to $298.15 \mathrm{~K}\left(25^{\circ} \mathrm{C}\right)$ which quite normal for space application. It is seen that the captured power $\mathrm{P}(\mathrm{w})$ achieves the values $20.5 \mathrm{~W}$ and $60 \mathrm{~W}$ corresponding to the maximum power point associated to the considered radiation (see Fig. 5). We can see also that the DC bus voltage $x_{3}$ is regulated to its desired value (30V). Fig.(11) shows that the current $i_{g}$ is sinusoidal and in phase with the source voltage $e_{g}$. which proves the required unity PF.

for all the results above, the sliding mode approach is able to maintain the output at optimum point and robust to the variation of the external conditions. Furthermore, it can almost reach the theoretical maximum power of known irradiance and temperature. 

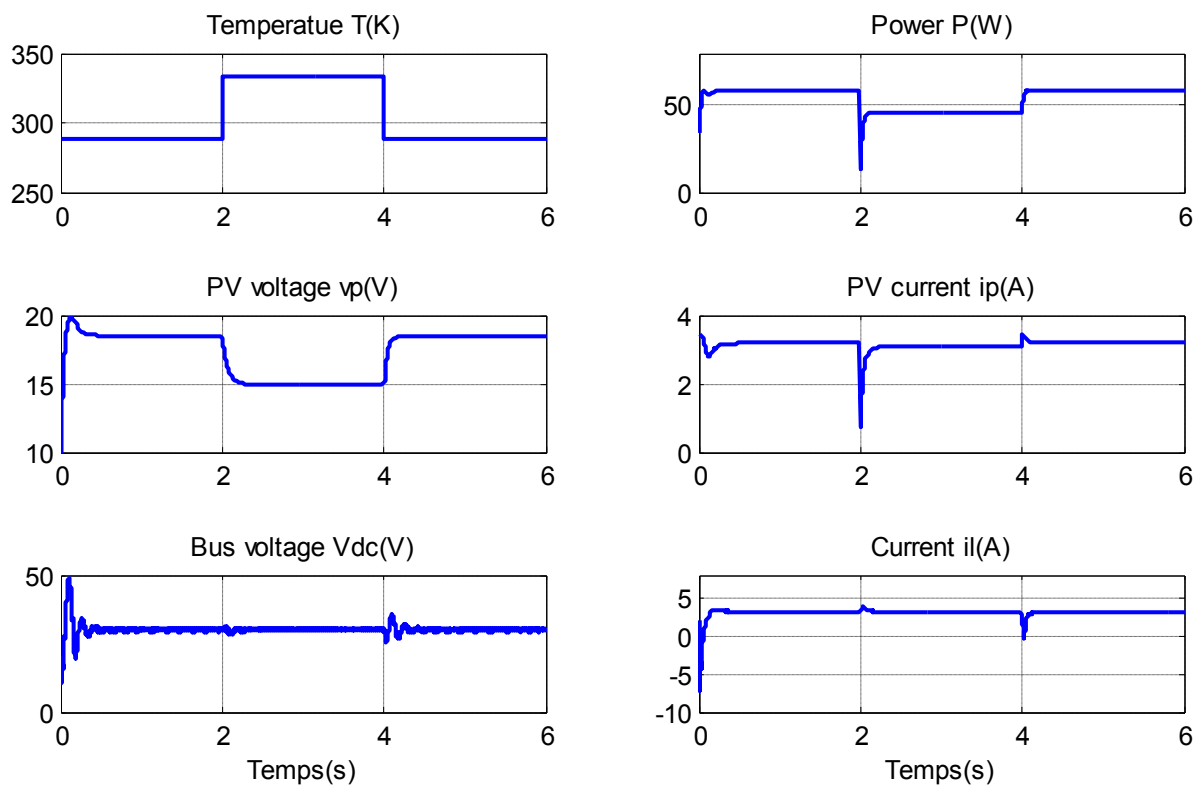

Fig.8: MPPT behavior in presence of temperature change



Fig 9. Unity PF behavior in presence of temperature changes
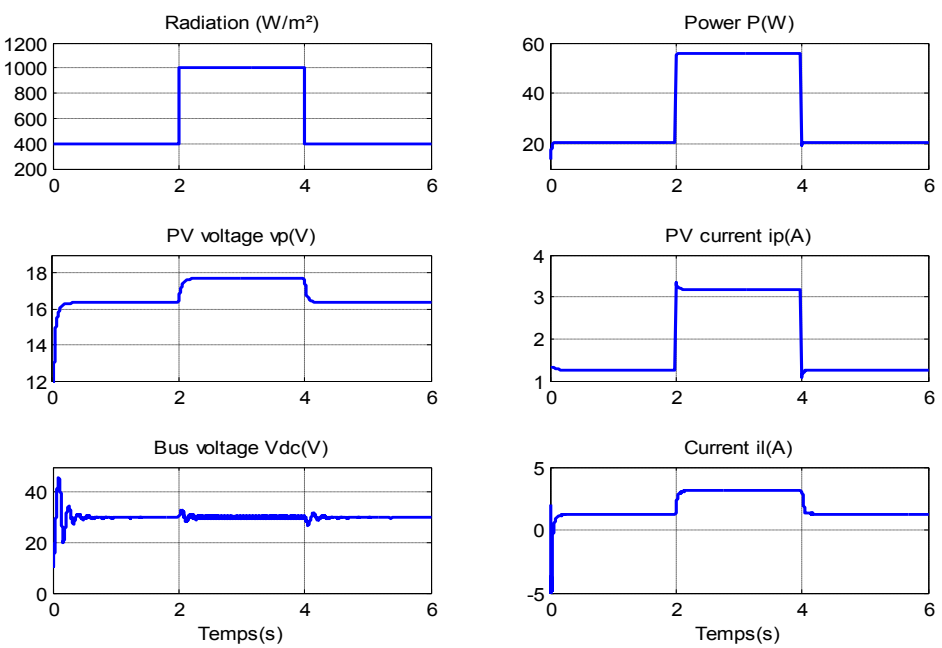

Fig. 10: MPPT behavior in presence of radiation change 


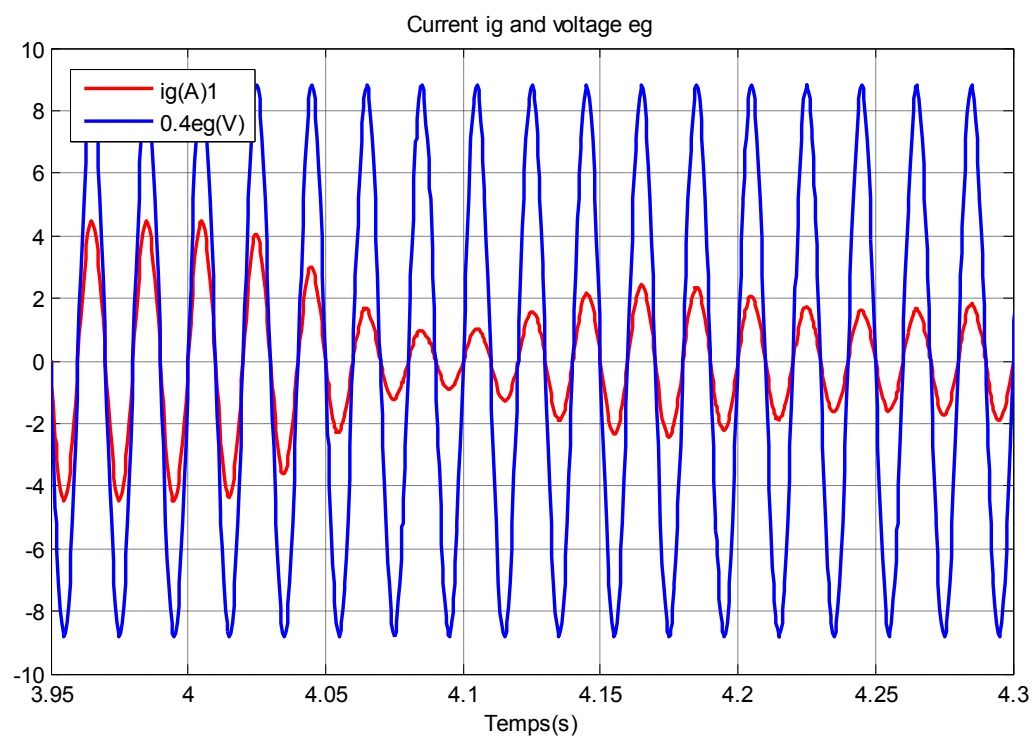

Fig 11. Unity PF behavior in presence of radiation changes

\section{CONCLUSION}

The problem of achieving MPPT in single phase grid- connected photovoltaic systems has been dealt with. Based on the averaged model (2.a-d), a new control strategy has been developed using the sliding mode approach. The developed controller is resorted to cope with the changing operating conditions (temperature and radiation) and to remedy to disadvantages of (RCC), (INCOND) and (P\&O) methods,

the sliding mode controller of proposition 1, guarantees the tracking objective despite the climatic conditions, Simulation results illustrates that the controller provide excellent asymptotic stability, a good behavior, and a perfect MPPT tracking. In future work, we will implement the control law on a real benchmark.

\section{References}

[1] Enrico Bianconi, Javier Calvente, Roberto Giral, Emilio Mamarelis, Giovanni Petrone, Carlos Andres Ramos-Paja, Giovanni Spagnuolo, Massimo Vitelli. (2013) "Perturb and Observe MPPT algorithm with a current con-troller based on the sliding mode". International Journal of Electrical Power and Energy Systems (IJEPES), Vol.44, pp: 346-356.

[2] Yong Yang, Fang Ping Zhao. (2011) "Adaptive perturb and observe MPPT technique for Grid connected Pho-tovoltaic Inverters." Procedia Engineering, Vol.23,pp:468-473.

[3] Panagiotis E. Kakosimos, Antonios G. Kladas. (2011) "Implementation of photovoltaic array MPPT through fixed step predictive control technique". Renewable Energy, Elsevier, Vol. 36, pp: 2508-2514.

[4] Lalili D, A. Mellit, N. Lourci, B. Medjahed, E.M. Berkouk.(2011) "Input output feedback linearization control and variable step size MPPT algorithm of a grid-connectedphotovoltaic inverter”. Renewable Energy, Elsevier,Vol.36,pp:3282-3291.

[5] Georgios Tsengenes, Georgios Adamidis. (2011) "Investigation of the behavior of a three phase grid-connected photovoltaic system to control active and reactive power". Electric Power Systems Research, Vol. 81, pp: 177-184.

[6] Trishan Esram, Jonathan W. Kimball, Philip T. Krein, Patrick L. Chapman, Pallab Midya. (2006) "Dynamic Maximum Power Point Tracking of Photovoltaic Arrays Using Ripple Correlation Control”. IEEE Transactions On Power Electronics, Vol. 21, No. 5, pp: $1282-1291$.

[7] T. Hiyama and K. Kitabayashi, "Neural network based estimation of maximum power generation from PV module using environment information," IEEE Trans. Energy Conv., vol. 12, no. 3, pp. 241-247, Sep.1997.

[8] A. B. G. Bahgat, N. H. Helwa, G. E. Ahmad, and E. T. E. Shenawy, "MPPT controller for PV systems using neural networks," Renew. Energy, vol. 30, no. 8, pp. 1257-1268, 2005.

[9] Khalil H Nonlinear Systems. Prentice Hall, NJ, USA

[10] Krstic M, I. Kanellakopoulos and P. Kokotovic. (1995) "Nonlinear and Adaptive Control Design". John Willey \& Sons,Inc.

[11] Enrique J.M., E. Duran, M. Sidrach-de-Cardona, J.M. Andujar. "Theoritical assessment of the maximum power point tracking efficiency of photovoltaic facilities with different converter topologies". Solar Energy, 81, pp. 31-38, 2007.

[12] Chen-Chi Chu, Chieh-Li Chen. "Robust maximum power point tracking method for photovoltaic cells: A sliding mode control approach". Solar Energy, 83, pp. 1370-1378, 2009.

[13] El Fadil, H. and Giri, F. "Climatic sensorless maximum power point tracking in PV generation systems". Control Engineering Practice Elsevier, Vol. 19, N.5, pp. 513-521, May 2011

[14] Krein P.T., Bentsman, J., Bass, R. M., \& Lesieutre, B. "On the use of averaging for analysis of power electronic system". IEEE Transactions on Power Electronics, 5(2), pp. 182-190, 1990. 